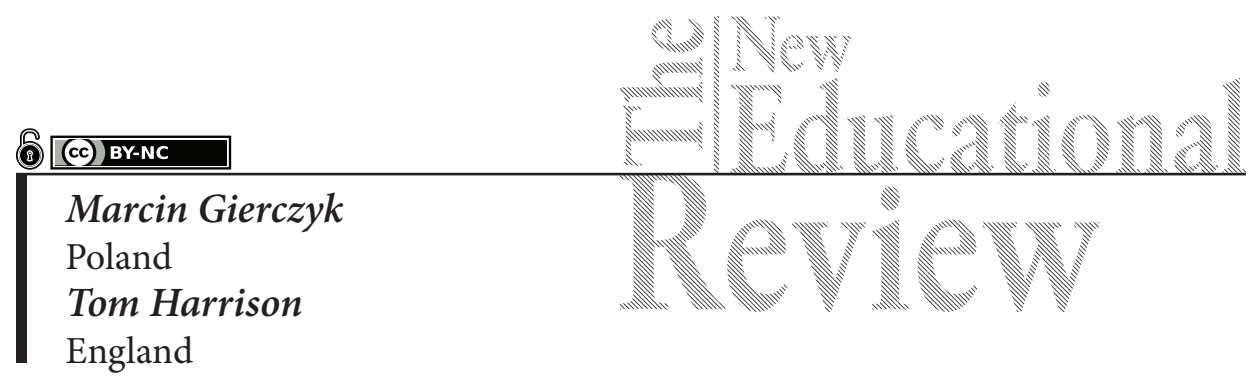

\title{
The Effects of Gender on the Ethical Decision-making of Teachers, Doctors and Lawyers
}

DOI: 10.15804/tner.2019.55.1.12

\begin{abstract}
The article presents the statistical findings of a study that investigated the effects of gender on the ethical decision-making of professionals. Ethical dilemmas were presented to 1,809 teachers, doctors and lawyers in the form of a questionnaire. The individuals were asked to choose a course of action and provide reasons for their choice. What was of particular interest was how the professionals prioritised different moral theories in their decision-making; namely, whether the reasons they gave were deontological, consequential or virtue ethical in nature. The findings are significant for those seeking to revise and improve professional ethical education and practice.
\end{abstract}

Keywords: ethical reasoning, ethical dilemmas, professional practice, gender

\section{Background}

Professional practitioners, including teachers, doctors and lawyers, are often seen as role models; they are relied upon for moral probity, often in complicated circumstances and in the face of conflicting demands (Jubilee Centre, 2016). They are expected to demonstrate practical wisdom, knowing and doing the right thing when faced with ethical dilemmas. However, recent high-profile scandals and examples of misconduct (Blond et al., 2015; Hall et al. 2011; Wald, 2004; Dixon-Woods et al., 2011) mean it is important to look more closely at the eth- 
ical decision-making of professionals (Arthur et al., 2014) and the way they are prepared and educated for the public aspect of the important roles they undertake (Harrison and Khatoon, 2017).

The presented article contributes to the existing literature on this topic through the secondary analysis of a data set consisting of 1,809 teachers', doctors' and lawyers' responses to an ethical dilemma relating to their profession. The effects of gender on how the professionals responded to the dilemma was under specific consideration. The focus of the analysis was on two areas of ethical decision-making. First, are there differences in the choice of actions made by male and female professionals? Who is more likely to follow established codes and protocols? Second, are male and female professionals more or less likely to adopt utilitarian, deontological or virtue ethical moral theoretical positions when explaining their reasons for taking a particular course of action? The findings of the presented study will support those seeking to revise professional ethical education and practice.

\section{Demographic differences and ethical decision-making in professional practice}

Professional practices, including teaching, medicine and law, are vital components of a nation's progress. Ethics is an essential element of these and other professional practices; the declared and applied moral values attribute to the profession. At the same time, professional ethics may have prohibitive, prescriptive, recommendatory or advisory forms. They may take the form of obligations towards others, obligations towards oneself, or society in general. There are normative expectations and values that are present in all professional practice. The three aforementioned professions encounter dilemmas that relate to these ethical standards, making the factors that affect professional decision-making an important area of research.

The literature pertaining to how different professionals undertake ethical reasoning is both complex and contradictory. Both historical and contemporary research indicates that factors such as gender, educational attainment, age, and work experience may be related to the development of an individual's ethical standards (Perryer and Jordan, 2002; Duncut, 2007; Chiu and Spindel, 2010; Nikoomaram et al., 2013; Ducut, 2007) and the way they deal with ethical dilemmas. The territory these studies cover is large and therefore both contextually and culturally dependent. Currently, academics disagree as to whether or not gender 
and age affect how members of different professions make ethical decisions when faced with dilemmas. Debates on this issue are long-running and academic luminaries including Aquinas, Aristotle and Freud commented on the different ways in which men and woman make judgments when faced with a moral issue.

\section{Demographic differences, ethical dilemmas and moral theory}

The dilemmas presented in this paper were designed to investigate how teachers, doctors and lawyers think when they are faced with morally problematic situations (Arthur et al., 2015). An ethical dilemma can also be understood as a problem situation, usually arising from a conflict of obligations among various relationships, in which issues of right and wrong are at stake, demanding complex decisions about appropriate responses (Campbell, 2000, p. 215; Shapira-Lischshinsky and Orland-Barak, 2009, p. 27). Although decision-making can happen intuitively via the unconscious system, and also emotionally and intuitively (Drumwright et al., 2015), the reasons given for a decision can be classified according to moral theories. The three most widely accepted and prominent moral theories are deontology, utilitarianism (consequentialism) and virtue ethics. Virtue ethics is a framework that focuses on the character of the moral agent rather than the rightness of an individual action (Gardiner, 2003, p. 297). Utilitarianism and deontology, on the other hand, ask the question: 'What should I do?" Deontology emphasises rules and duties for doing the right things, and utilitarianism requires a calculated assessment of consequences. Previous analysis of the data under consideration in this paper found that professionals draw on all three positions when making a decision, to a varying degree and at different times (Arthur et al., 2015a, b and c).

\section{The study}

The findings presented in this paper are based on a secondary analysis of data collected from three research projects conducted by the Jubilee Centre for Character and Virtues, an interdisciplinary research centre focusing on character, virtues and values, based at the University of Birmingham in the UK. This survey forms part of the Centre's research project on virtues and values in the professions, which explores the role of virtues and values in medicine, law and teaching among new trainees, graduates and established professionals. The Centre's reports Virtuous Character for the Practice of Law, The Good Teacher, and Virtuous Medical Practice 
(Arthur et al., 2015a, 2015b, 2015c) examine the place of character and values in the legal, medical and teaching professions in Britain.

A study of the three reports presented the possibility of a secondary analysis to investigate whether there are differences among genders and professions. The secondary analysis involved the use of existing data, collected for a prior study (Hinds et al., 1997; Long-Sutehall et al., 2010, 336) in order to find answers to a new, overarching research question: Is ethical decision-making and virtue-based, rule-based and consequence-based reasoning differentiated by gender and age among teachers, doctors and lawyers?

The full online questionnaire consisted of four sections. For this paper, a secondary analysis was conducted of section two, where participants gave their responses to six dilemmas relating to their profession. In order to compare the different ethical dilemmas presented to each profession, one dilemma - whether lawyers, doctors and teachers would agree with a pupil, patient, and client request - was chosen by authors from each profession (cf., Table 1). The ethical dilemmas in the questionnaire were designed to provide some indication of how teachers, doctors and lawyers at different stages of their careers would choose to act in hypothetical situations and how they might explain their reasons for acting.

Table 1. Summary of the ethical dilemmas

\begin{tabular}{ll}
\hline Profession & Summary of the dilemma \\
\hline Teachers & $\begin{array}{l}\text { Children wanted to explore snow during a lesson. This would disrupt the } \\
\text { planned programme, which was further complicated because snow was } \\
\text { a new experience for some children. The teacher had to choose between } \\
\text { disrupting the lesson or ignoring the children's requests. }\end{array}$ \\
\hline Doctors & $\begin{array}{l}\text { Would doctors be willing to satisfy a patient's personal request for a flu } \\
\text { vaccine, the patient saying, "I simply can't catch the flu this season. My boss } \\
\text { has already told me that any time off work over Christmas and I'll be out of } \\
\text { my job!" }\end{array}$ \\
\hline Lawyers & $\begin{array}{l}\text { Would lawyers be willing to satisfy a client's personal request to stop legal } \\
\text { proceedings against the father of her children, even though the children are } \\
\text { at risk of physical abuse? The client intends to move with the children back } \\
\text { to their father. }\end{array}$ \\
\hline
\end{tabular}

\section{Participants and methods}

The original data comprised three separate databases for each profession (teachers, doctors and lawyers). Data was collected using an online survey over the period 2014-2015 from 1,809 respondents (i.e., 564 doctors, 728 lawyers and 
517 teachers). The survey population comprised 1,137 women $(62.9 \%)$ and 682 men $(37.1 \%)$.

\section{Statistical analysis}

The collected data was transferred to SPSS version 21, checked, cleaned and readied for analyses. Analyses included descriptive analysis, cross-tabulation, correlation and factor analysis. To analyse the ethical dilemmas section, we conducted a series of tests using SPSS, including the Mann-Whitney $U$ test to see where any differences of statistical significance lay. The test was used as a nonparametric alternative to the one-way ANOVA to examine whether there was a significant difference (relationship) between the option and reason of a dilemma and gender and age.

\section{Findings}

The three dilemmas, for teachers, doctors and lawyers, were broadly of a similar nature; pupils, patients and clients ask professionals to break the protocol for their personal needs. However, the precise context and circumstances for each dilemma were different, therefore each was analysed separately. The findings are presented below; looking first at differences in gender and then age.

Is ethical decision-making and virtue-based, rule-based and consequence-based reasoning differentiated by gender among teachers, doctors and lawyers?

\section{Teachers}

The question posed in this dilemma was whether the teachers would be willing to be flexible in letting children experience snow in the playground even when this meant interrupting a planned lesson. The participants could choose option A, which favoured curriculum flexibility, telling the pupils to put on their coats, hats and gloves and take them outside to experience the snow; or option $\mathrm{B}$, which was to follow the established duties and allow the children to look out of the window for a few minutes but then ask them to sit down and concentrate on the lesson.

Results show a significant relationship between the option chosen and gender $(\chi 2=7.963, p=0.005)$, with a mean rank of 274.97 for the male teachers. This means 
the male teachers are more likely to follow the established protocol than the female teachers; they are less willing to do what pupils request.

The conclusion is confirmed by looking at the percentage of the male and female teachers choosing each option (cf., Figure 1). Here, the finding contradicts observations made for doctors and lawyers in their dilemmas. 59.2\% of male teachers adhered to established duties in regards to curriculum flexibility (opting to continue the lesson), whilst $59.1 \%$ of females opted for the alternative (letting the children play in the snow). As we can see from chart 3 and statistical analysis, female teachers were more willing to do what the pupils requested, indicating females prefer curriculum flexibility in this case.

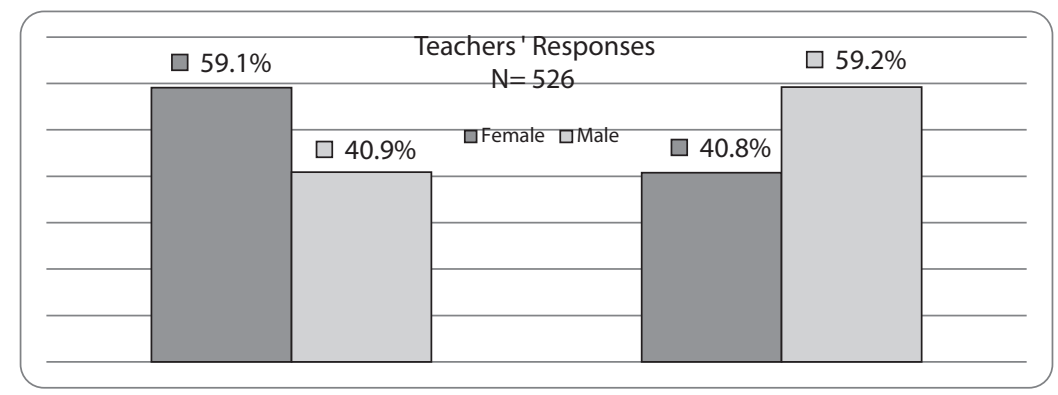

Figure 1. Teachers' overall reasoning by gender

The second analysis looked at the reasons given for choosing either option $\mathrm{A}$ or B. For this analysis, the virtue-, rule- and consequence-based reasons (for A and B) were compiled together. The results show a significant relationship between the given reason in the ethical dilemma and gender for the virtue-based reason $(\mathrm{U}=360312.500, \mathrm{p}=.023)$ and consequences $(\mathrm{U}=358257.000, \mathrm{p}=.007)$, with a mean rank of 940.38 for the male teachers and 924.10 for the female ones. This means the female teachers were more likely to prioritise virtue-based reasoning than the male teachers. Also, the female teachers were less worried about the consequences of their actions than the male teachers.

\section{Doctors}

The question posed in this dilemma was whether the doctors would be willing to satisfy a patient's personal request for a flu vaccine, the patient saying, 'I simply can't catch the flu this season. My boss has already told me that any time off work 
over Christmas and I'll be out of my job!'. The participants could choose option B, which was to follow the established protocol and not give the vaccine; or option A, which was not to follow the established protocol and give the vaccine. The results show a significant relationship between the option chosen and gender $(\chi 2=7.445$, $\mathrm{p}=0.006$ ), with a mean rank of 293.80 for the females. The female doctors are more likely to follow the established protocol than the male doctors; they are less willing to do what the patient requests.

This conclusion is confirmed

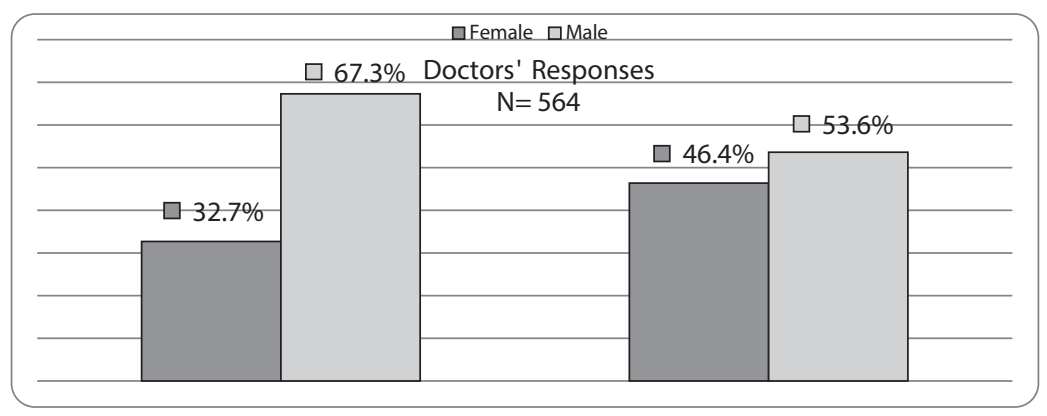

Figure 2. Doctors' responses to dilemma (\%) by gender

$53.6 \%$ of the female doctors adhered to the established protocol, whilst $67.6 \%$ of the male doctors opted for the alternative. The second analysis looked at the reasons given for choosing either option $\mathrm{A}$ or B. For this analysis, the virtue-, ruleand consequence-based reasons (for $\mathrm{A}$ and $\mathrm{B}$ ) were compiled together. The results of the Mann-Whitney $U$ test indicate that there is not a statistically significant difference (relationship) between the given reason and gender.

\section{Lawyers}

The lawyers were asked, in their dilemma, if they would grant a female client's request to stop unspecified legal proceedings against the father of her children. The client further indicated she planned moving back in with the man and would be returning with the children, even though this might put the children at risk of physical abuse. The participants could choose option A, which was not to follow the established protocol and withdraw the proceedings; or option $\mathrm{B}$, which was to follow the established protocol and report the matter to social services. 
The results show a significant relationship between the option chosen and gender $(\chi 2=15.245, \mathrm{p}<0.001)$, with a mean rank of 381.67 for the female lawyers. The female lawyers are more likely to follow the established protocol than the male lawyers; they are less willing to do what the client requests. This conclusion is confirmed by looking at the percentage of the male and female lawyers who chose each option (cf., Figure 3). 55.3\% of the female lawyers followed the established protocol, whilst $61.5 \%$ of the male lawyers opted for the alternative option.

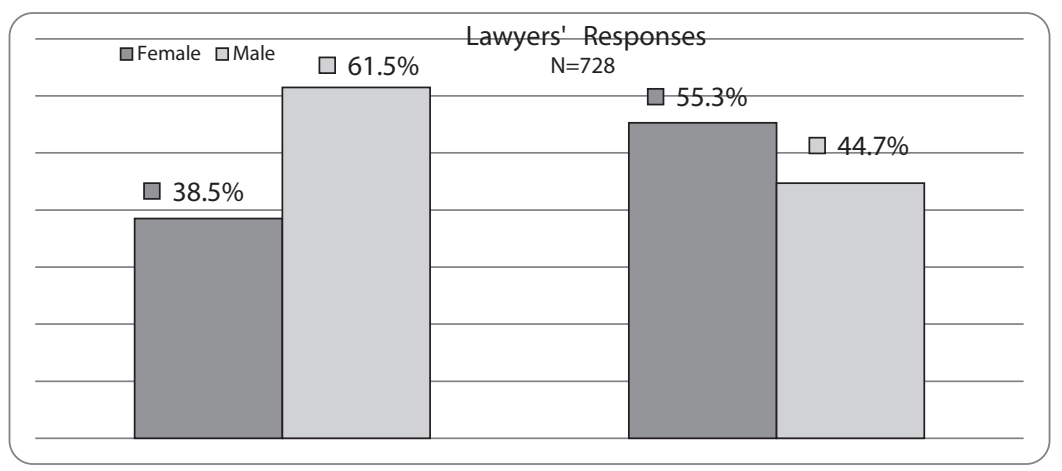

Figure 3. Lawyers' responses to dilemma (\%) by gender

The second analysis looked at the reasons given for choosing either option A or B. For this analysis, the virtue-, rule- and consequence-based reasons (for A and B) were compiled together. The results of the Mann-Whitney $U$ test indicated that there is not a statistically significant difference (relationship) between the stated reason and gender.

\section{Overall findings}

The results of the study show that gender may be a factor of the choice of the action that the lawyers, doctors and teachers take when faced with ethical dilemmas.

The most prominent findings are:

a) The male teachers are more likely to follow the established protocol than the female teachers.

b) The female teachers are more likely to prioritise virtue-based reasoning than the male teachers and are less worried about the consequences of their actions than the male teachers. 
c) The female doctors are more likely to follow the established protocol than the male doctors.

d) The female lawyers are more likely to follow the established protocol than the male lawyers.

e) The male and female lawyers and doctors are motivated in similar ways by virtue-, consequence- and rule-based reasoning.

\section{Discussion}

Several previous studies have demonstrated a difference in how men and woman respond to ethical dilemmas (e.g., Morrell and Jayawardhena, 2013; Tilley 2010; Becker and Ulstad, 2007; Wilborn et al., 2007; Nikoomaram et al., 2013; Ruegger and King, 1992; Valentine and Rittenburg, 2007). Indeed, a famous critique of Kohlberg's once powerful stage theory of moral reasoning rested on the premise that he failed to take account of gender differences in processing and responding to dilemmas (Gilligan, 1993). To date, the picture presented by the data is both confusing and often contradictory. This new research contributes to the existing body of evidence and shows that gender can be a predictor of how teachers, doctors and lawyers respond to ethical dilemmas, and supports the findings of several previous studies (Tilley, 2010; Becker and Ulstad, 2007; Wilborn et al., 2007; Dawson, 1995; Ruegger and King, 1992). These previous studies had indicated, e.g., that males are more likely to break rules than females (McCabe et. al., 2006). Furthermore, research into executives in the USA and Spain found no gender differences with the ethical decision but noted differences with the intention to act ethically, where females acted more ethically than males (Valentine and Rittenburg, 2006, p. 125). The research extends the existing knowledge in one significant way: it is focused primarily on individuals from three professional practices and, therefore, is more targeted than most previous studies.

Interestingly, previous research shows that women are more likely to follow the established protocol than men (Morrell, 2013; Tilley, 2010). In this study, however, we found that although this is the case for the lawyers and doctors, the female teachers are more inclined to ignore the established protocol than their male counterparts. This might be an anomaly due to the nature of the dilemma, but it is illuminating to see the difference in decision-making between male and female teachers.

In this study, we found that in most cases professionals of different genders tended to prioritise virtue-based reasoning to a similar extent when explaining 
their adoption of a particular course of action. The main difference was between the female teachers and male lawyers. The female teachers were more likely to give virtue-based reasons for breaking the established protocol than the male ones. This is significant, as schools are increasingly considered as institutions where professional judgment and decision-making are compromised due to the increased emphasis on compliance with policies (Cooke and Carr, 2014). These findings offer significant food for thought in this area.

\section{Conclusion}

The secondary analysis of the data collected by the Jubilee Centre for Character and Virtues is valuable for several reasons. It yielded significant results, which provide new insights into how male and female teachers, doctors and lawyers make choices when faced with dilemmas. Many previous studies focused on business and accounting; this research sheds light on some largely under-explored groups. It also highlights how different professionals prioritise moral theory when giving their reasons for following a particular course of action. The findings that reveal when professionals are willing to break the established protocol and provide virtue-based reasons for their actions are of particular interest. They challenge the prevalence of codes of conduct in professional ethics, which primarily seek to safeguard the rights of pupils, patients and clients by specifying the responsibilities of service providers with respect to such rights. However, it is increasingly apparent that 'the value and effectiveness of sound professional practice of institutional regulations and codes of conduct are limited' (Jubilee Centre, 2016). It is precisely when professionals are called to make ethical decisions that these limitations are highlighted, as often there is no rule or code that covers the precise situation. An understanding of how male and female teachers, doctors and lawyers make virtue-based decisions is vital for the continued flourishing of these professions.

\section{References}

Arthur, J., Kristjansson, K. Thomas, H., Ignatowicz, A., and Qiu, T. (2015). Virtuous Medical Practice. Research Report. The Jubilee Centre for Character and Virtue

Arthur, J., Kristjansson, K., Thomas, H., Holdsworth, M., Confalonieri, L.B., and Qiu, T., (2014). Virtuous Character for the Practice of Law: Research Report. Retrieved from http://www.jubileecentre.ac.uk/userfiles/jubileecentre/pdf/Research\%20Reports/Virtuous_Character_for_the_Practice_of_Law.pdf [Accessed 12 Jun 2017]. 
Arthur, J., Kristjansson, K., Cooke, S., Brown, E., Carr, D., and Damon, W. (2015). The Good Teacher: Understanding Virtues in Practice. Retrieved from http://www.jubileecentre. ac.uk/userfiles/jubileecentre/pdf/Research\%20Reports/The_Good_Teacher_Understanding_Virtues_in_Practice.pdf [Accessed 12 Jun 2017].

Becker, D.A., Ulstad, I. (2007). Gender Differences in Student Ethics: Are Females Really More Ethical? Plagiary: Cross - Disciplinary Studies in Plagiarism, Fabrication, and Falsification. 77-91.

Blond, P., Antonacopoulou, E. and Pabst, A. (2015) In Professions We Trust: Fostering Virtuous Practitioners in Teaching, Law and Medicine, London: ResPublica, [Online], Available at: www.respublica.org.uk/wp-content/uploads/2015/02/In-Professions-We-Trust. pdf [Accessed: 20 June 2015].

Campbell, E. (2000) Professional ethics in teaching: Towards the development of a code of practice. Cambridge Journal of Education, 30(2) 203-221.

Chiu, Y, and Spindel, B. (2009). Effect of Age and Gender on Ethical Decision Making. Retrieved from https://pdfs.semanticscholar.org/d294/6d8664468d2ef68b0560b7d2d5c372a92e67.pdf [Accessed 26 Jun 2017].

Cooke, S. and Carr, D. (2014). Virtue, Practical Wisdom and Character in Teaching. British Journal of Educational Studies 62(2): 91-110.

Crow S.M.. Fok L.Y., Hartman S.J. and Payne D.M. (1991) Gender and values: What is the impact on decision making? Sex Roles vol. 25, Issue 3-4, pp 255-268

Dalton, D and Ortegren M. (2011). Gender Differences in Ethics Research: The Importance of Controlling for the Social Desirability Response Bias. Journal of Business Ethics, 103(1): 73-93.

Dawson, N. (1995). Women and Men, Morality and Ethics. Retrieved from http://homepages.se.edu/cvonbergen/files/2013/01/Women-and-Men-Morality-and-Ethics.pdf [Accessed 01. Sep 2017].

Dixon-Woods, M., Yeung, K. and Bosk, C.L. (2011) 'Why is UK Medicine No Longer a Self-regulating Profession? The role of scandals involving "bad apple" doctors', Social Science and Medicine, vol. 73, no. 10, pp. 1452-145

Drumwright, M., Prentice, R and Biasucci, C. Behavioral Ethics and Teaching Ethical Decision Making. Decision Sciences Journal of Innovative Education, 13(3): 431-458.

Ducut, J.D. (2007). Nurturing the ethical reasoning of leaders: The illumination of ethics education, demographics, and teaching methods. Dissertation Abstracts International Section A: Humanities and Social Sciences, 67(7-A): 2462.

Ede, E., Panigrahi, B., Stuart, J. and Calcich, S. (2000). Ethics in small minority business, Journal of Business Ethics, 26: 133-146.

Ford, R.E. and Richardson W.D. (1994). Ethical Decision Making: A Review of the Empirical Literature. Journal of Business Ethics, 13(3): 205-221.

Gardiner, P. (2003) A virtue ethics approach to moral dilemmas in medicine. Journal of Medical Ethics, 29: 297-302

Gilligan, C. (1993). In a different voice: psychological theory and women's development. Cambridge, Mass.: Harvard University Press. 
Hall, P.A., Wixon, J., Poulsom, R. (2011)'The Journal of Pathology's Approach to Publication Ethics and Misconduct,'The Journal of Pathology, vol. 223, no. 4, pp.447-449.

Harrison T., Khatoon B. (2017) Virtue, Practical Wisdom and Professional Education. A Pilot Intervention Designed to Enhance Virtue Knowledge, Understanding and Reasoning in Student Lawyers, Doctors and Teachers.Research Report. Available at: http://www.jubileecentre.ac.uk/userfiles/jubileecentre/pdf/Research\%20Reports/ Interventions.pdf [Accessed: 1 January 2018].

Hinds, P.S., Vogel, R.J., Clarke-Steffen, L. (1997). The possibilities and pitfalls of doing a secondary analysis of a qualitative data set. Qualitative Health Research, 7(3): 408-24. Jubilee Centre for Character and Virtues (2017) A Framework for Character Education in Schools, University of Birmingham, Jubilee Centre for Character and Virtues. Retrieved from http://www.jubileecentre.ac.uk/userfiles/jubileecentre/pdf/character-education/ Framework\%20for\%20Character\%20Education.pdf [Accessed 26 Jun 2017].

Kristjánsson, K. (2015). Aristotelian character education. London: Routledge

Long-Sutehall, T., Sque M. and Addington-Hall J. (2010). Secondary analysis of qualitative data: a valuable method for exploring sensitive issues with an elusive population? Journal of Research in Nursing, 16(4): 335-344.

Mayhew R., (2004) The Female in Aristotle's Biology. Chicago: University of Chicago Press. McCabe A.C. Ingram R. Dato-on M.C. (2006) The Business of Ethics and Gender. Journal of Business Ethics. 64: 101-116

Morrell, K. Jayawardhena, Ch. (2010) Fair trade, ethical decision making and the narrative of gender difference. Business Ethics: A European Review, 19(4): 393-407.

Nikoomaram, H. , Roodposhti F.R., Ashlaghi A.T., Lotfi F.H., Taghipourian Y. (2013). The Effects of age, gender, education level and work experience of accountant on ethical decision making by using fuzzy logic. International Research Journal of Applied and Basic Sciences, 4(6): 1559-1571.

Nolan M. (2000) The Aristotelian Background to Aquinas's Denial that ,Woman is a Defective Male' The Thomist 64 (2000): 21-69. Available at: http://www.thomist.org/ jourl/2000/January/2000\%20Jan\%20A\%20Nolan.pdf [Accessed: 1 January 2018]

Perryer, Ch.,Jordan, C., (2002) The Influence of Gender, Age, Culture and Other Factors on Ethical Beliefs: A Comparative Study in Australia and Singapore. Public Administration and Management: An Interactive Journal, 7(4): 367-382.

Peterson, D., Rhoads, A. and Vaught, B.C. (2001). Ethical beliefs of business professionals: A study of gender, age and external factors. Journal of Business Ethics, (31)3: 225-232

Ruegger D., King E. (1992). A Study ofthe Effect of Age and Gender upon Student Business Ethics. Journal of Business Ethics, 11(3): 179-186.

Sanger, M.N., Osguthorpe, R.D. (2013) 'Modeling as Moral Education: Documenting, analyzing, and addressing a central belief of preservice teachers', Teaching and Teacher Education, vol. 29, pp.167-176

Shapira-Lischshinsky, O., Orland-Barak L. (2009). Ethical Dilemmas in Teaching: The Israeli Case. Education and Society, 27(3): 27-45. 
Sockett, H. (2012) Knowledge and Virtue in Teaching and Learning: The primacy of dispositions, New York: Routledge.

Tilley, E. (2010) Ethics and gender at the point of decision-making: An exploration of intervention and kinship. Prism, 7(4): 1-19. http://www.prismjournal.org/fileadmin/ Praxis/Files/Gender/Tilley.pdf [Accessed: 1 January 2019]

Valentine, T., Rittenburg, T. (2006). The Ethical Decision Making of Men and Women Executives. International Business Situations Journal of Business Ethics, 71(2): 125-134.

Vitell. S.J., Singh J., Paolillo J.G.P. (2007).Consumers' ethical beliefs: the roles of money, religiosity and attitude toward business. Journal of Business Ethics, 73(4):369-79.

Wald, E. (2004) 'Lawyers and Corporate Scandals', Legal Ethics, vol. 7, no. 1, pp.54-84.

Wilborn, L.R., Brymer, R., Schmidgall, R. (2007). Ethical Decisions and Gender Differences of European Hospitality Students. Tourism and Hospitality Research, 7(3/4): 230-241.

Willemse, M., Lunenberg, M., Korthagen, F. (2008) 'The Moral Aspects of Teacher Educators' Practices', Journal of Moral Education, vol. 37, no. 4, 445-466. 